\section{1}

\title{
Predictors of Depression and Anxiety Symptoms in Brazil during COVID-19
}

\author{
Stephen X. Zhang 1,*, Hao Huang ${ }^{2}$, Jizhen Li ${ }^{3}$, Mayra Antonelli-Ponti ${ }^{4}$, Scheila Farias de Paiva ${ }^{5,6}$, José Aparecido \\ da Silva ${ }^{7}$
}

${ }^{1}$ Faculty of Professions, University of Adelaide, Adelaide SA 5000, Australia; stephen.x.zhang@gmail.com 2 School of Business Administration, Southwestern University of Finance and Economics, Chengdu 611130, China; fizz-huang@qq.com

${ }^{3}$ Research Center for Competitive Dynamics and Innovation Strategy, School of Economics and Management, Tsinghua University, Beijing 100084, China; lijzh@sem.tsinghua.edu.cn

${ }^{4}$ University Center Barão de Mauá, Ribeirão Preto, SP, Brazil; antonelli.may@alumni.usp.br

${ }^{5}$ Federal University of Sergipe (UFS), Lagarto, SE, Brazil

${ }^{6}$ Federal University of Juiz de Fora (UFJF), Juiz de Fora, MG, Brazil; spaivafono@yahoo.com.br

7 Unit of Psychobiology, University of Sao Paulo in Ribeirao Preto, SP, Brazil; jadsilva@ffclrp.usp.br

* Correspondence: stephen.x.zhang@gmail.com; 9-27 Nexus10 Tower, 10 Pulteney St, Adelaide SA 5000, Australia

\begin{abstract}
The COVID-19 pandemic in Brazil is extremely severe, and Brazil has the third-highest number of cases in the world. The goal of the study is to identify the prevalence rates and several predictors of depression and anxiety in Brazil during the initial outbreak of COVID-19. We surveyed 482 adults in 23 Brazilian states online on 9-22 May 2020, and found $70.3 \%$ of the adults $(\mathrm{N}=339)$ had depressive symptoms and $67.2 \%(\mathrm{~N}=320)$ had anxiety symptoms. The results of multi-class logistic regression models revealed that females, younger adults and those with fewer children had a higher likelihood of depression and anxiety symptoms; adults who worked as employees were more likely to have anxiety symptoms than those who were self-employed or unemployed; adults who spent more time browsing COVID-19 information online were more likely to have depression and anxiety symptoms. Our results provide preliminary evidence and early warning for psychiatrists and healthcare organizations to better identify and focus on the more vulnerable sub-populations in Brazil during the ongoing COVID-19 pandemic.
\end{abstract}

Keywords: COVID-19; Brazil; anxiety; depression; predictors; risk factors

\section{Introduction}

Since the initial outbreak of COVID-19 in late 2019, the COVID-19 epidemic has caused a devastating blow to the world, including the death of millions of people and the setback of socioeconomic functions of society and individual daily life [1]. It was reported that 2.6 billion people experienced emotional and economic shocks; this number even exceeds the number of people affected by the Second World War. Brazil has one of the highest rates of COVID-19 cases and deaths in the world by so far. Since the beginning of 2020, the pandemic has had a great impact on the normal life of people in Latin America [2-4], including its largest country Brazil [5,6]. The COVID-19 pandemic not only threatens people's health but also impacts on the mental health of the public [7-10]. On the one hand, the uncertainty of the initial route of transmission and treatment has exacerbated people's fear during the COVID-19 crisis [11]. On the other hand, the social distancing and confinement measures during the COVID-19 pandemic can lead to symptoms of anxiety and depression [12-17]. Although several studies have documented high prevalence rates of mental health symptoms in various parts of the

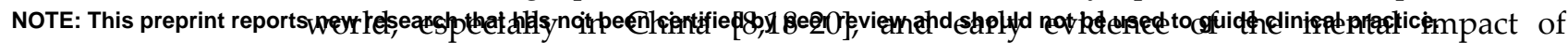
COVID-19 in Brazil was reported in a timely manner [21], there are few evidence-based 
studies containing critical predictors of mental issues in adults under a full-on COVID-19 outbreak in Brazil. As the devastating COVID-19 crisis continues in Brazil, it is crucial and urgent to investigate the risk factors for mental health issues in Brazilian adults.

In this study, we use three types of predictors: demographic factors, health factors and COVID-specific factors. The research on mental health in the COVID-19 pandemic has focused on demographic characteristics as predictors [22-24]. For example, gender [25-27], age [28], education [29], occupation [30] and number of children [31] have been the key predictors. Based on the existing research, we examined the key demographic factors such as gender, age, education, occupation and number of children as the predictors in this study. Good health and behaviors such as exercise [8] can improve individuals' mental health. On the contrary, individuals with chronic health problems are more likely to encounter mental disorders [32]. Hence, we examined exercise and the presence of chronic diseases as predictors of mental health under the COVID-19 pandemic. Of COVID-19 specific factors, the emerging literature on COVID-19 mental health has uncovered that the occurrence of symptoms related to or similar to COVID-19 increases individuals' psychological risk [33]; and information on COVID-19 on the internet is an important predictor of people's fear or panic over COVID-19 [26]. Therefore, we include the symptoms of COVID-19 infection and the hours per day spent browsing COVID-19 information online as COVID-19-related predictors in this study.

This study attempts to identify the predictors of depression and anxiety symptoms of Brazilian people during the COVID-19 pandemic to provide preliminary evidence and early warning for psychiatrists and healthcare organizations to identify the more vulnerable sub-populations to enable more targeted and timely mental intervention.

\section{Materials and Methods}

\subsection{Design}

We launched an online survey to study the mental health of adults in Brazil during the COVID-19 pandemic on 9-22 May 2020. The survey was conducted through a link to Google Forms to preserve social distancing protocols and to reach people across Brazil's large and diverse regions. We used the non-probabilistic sampling technique of quota sampling to approximate a representative sample of Brazilian adults. Quota sampling is one of the most popular sampling methods and a viable method [34] to conduct online surveys across all regions of Brazil without access to a probabilistic panel. The use of quota sampling by age, gender and social class was effective and viable in our case to obtain a sample that represents the population in Brazil. The study sampled adults aged 18 years or older by unclustered systematic random samples from all 23 states in Brazil. The survey, in Brazilian Portuguese, contained a cover page, which explained the purpose of the study and all the participants consented before starting the survey. From the 857 adults who participated in the study, we received a total of 482 valid responses for a response rate of $56.2 \%$. Ethical approval for this research was received from the Ethics Review Board (CAAE: 31703720.9.1001.0008) at University of São Paulo.

\subsection{Variables and instruments}

The survey collected socio-demographic information of individual adults, including their gender, age, education level, employment status, work and family status. The survey also collected basic health conditions such as chronic health issues [8] and lifestyle behaviors such as daily exercise time [33]. The descriptions of these variables are in Table 1.

The outcome variables are depression [35] and anxiety [36]. The Patient Health Questionnaire-9 (PHQ-9) is one of the most established depression scales, which captures the frequency and severity of depression related symptoms in the past two weeks, with a total of 9 items. In this study, the internal consistency coefficient of PHQ-9 is 0.902 . 
A sample item is: in the past two weeks, how many days did you have a lack of appetite or did you overeat $(0=$ no day $1=$ less than a week $2=$ a week $3=$ almost every day $)$ ?

The Generalized Anxiety Disorder scale (GAD-7) is a simple and effective way to evaluate generalized anxiety disorder (GAD), a mental disorder with long-term persistent anxiety and excessive anxiety as the core symptoms. In this study, GAD-7 has 7 items, and the internal consistency coefficient is 0.937. A sample item is: in the past 2 weeks, how often did you feel nervous, anxious or very tense $(0=$ rarely $1=$ some days 2 $=$ more than half the days $3=$ almost every day)?

\subsection{Statistical strategy}

All the data processing was completed in SPSS 23.0, and a two-tailed $p<.05$ was considered statistically significant. First, we report the descriptive statistics on the study variables and the distributions of adults by varying severities of depression symptoms $(0-5=$ minimal, $6-8=$ mild, $9-14=$ moderate, $15-27=$ severe $)[25,26,38]$ and anxiety symptoms $(0-4=$ minimal, $5-9=$ mild, $10-14=$ moderate, $15-21=$ severe $)$ [36], the maximum score is 27 for depression and 21 for anxiety. A score of PHQ-9 above 5 is considered mild depressive symptoms [35]; and mild anxiety symptoms are considered at the score of GAD-7 above 4 [36]. Second, univariate analysis (i.e. Mann-Whitney test, One-way Anova test and Kruskal-Wallis test) and an ordinal multi-class logistic regression model were used on the predictors of adults' mental health issues $[39,40]$.

\section{Results}

The descriptive statistics are shown in Table 1 . In this sample, $45.9 \%$ of the adults were male and $54.1 \%$ were female, and the average age was 36.69 years old $(\mathrm{SD}=13.50)$. Over $70 \%(72.5 \%)$ were doing or had college degrees or above, and just under half $(46.5 \%)$ were employees in their employment status. Almost half $(46.7 \%)$ worked at home. The average number of children under 18 years old was 0.54 . In terms of personal health status, $24.3 \%$ had some chronic health issues. The average daily exercise time in the past two weeks was 1.08 hours $(\mathrm{SD}=1.50)$. Additionally, 3.3\% reported having the symptoms of COVID-19 infection, and 1.37 hours (SD = 1.33) on browsing information on COVID-19 online per day in average across the whole sample. Over 70\% (70.3\%) of the adults $(\mathrm{N}=339)$ had depressive symptoms (PHQ-9 score $>5)$ and $22.8 \%(\mathrm{~N}=110)$ had experienced severe depression (PHQ-9 score $=15-27) ; 67.2 \%(\mathrm{~N}=320)$ had anxiety symptoms (GAD-7 score $>4)$ and $17.2 \%(\mathrm{~N}=82)$ had experienced severe anxiety (GAD-7 score $=$ 15-21). 
medRxiv preprint doi: https://doi.org/10.1101/2021.06.28.21259409; this version posted July 3,2021 . The copyright holder for this preprint (which was not certified by peer review) is the author/funder, who has granted medRxiv a license to display the preprint in perpetuity.

It is made available under a CC-BY-NC-ND 4.0 International license.

Table 1. Descriptions of the participants $(\mathrm{N}=482)$.

\begin{tabular}{|c|c|c|}
\hline Variables & Count or mean & Percentage \\
\hline Gender & - & - \\
\hline Male & 221 & $45.9 \%$ \\
\hline Female & 261 & $54.1 \%$ \\
\hline Age (Mean \pm SD) & $36.69 \pm 13.50$ & - \\
\hline Education & - & - \\
\hline Middle school & 5 & $1.0 \%$ \\
\hline High school & 128 & $26.6 \%$ \\
\hline College/university & 195 & $40.5 \%$ \\
\hline Postgraduate & 154 & $32.0 \%$ \\
\hline Employment status & - & - \\
\hline Self-employed & 97 & $20.1 \%$ \\
\hline Employee & 224 & $46.5 \%$ \\
\hline Student & 112 & $23.2 \%$ \\
\hline Unemployed & 26 & $5.4 \%$ \\
\hline Retired & 23 & $4.8 \%$ \\
\hline $\begin{array}{c}\text { Number of children under the } \\
\text { age of } 18(\text { Mean } \pm \text { SD) }\end{array}$ & $0.54 \pm 0.79$ & - \\
\hline Chronic health issue & - & - \\
\hline Yes & 117 & $24.3 \%$ \\
\hline No & 365 & $75.7 \%$ \\
\hline $\begin{array}{l}\text { Exercise hours per day in the } \\
\text { past two weeks (Mean } \pm \text { SD) }\end{array}$ & $1.08 \pm 1.50$ & - \\
\hline Work situation & - & - \\
\hline Worked in the usual place & 120 & $24.9 \%$ \\
\hline Worked at home & 225 & $46.7 \%$ \\
\hline $\begin{array}{l}\text { Did not work due to COVID-19 } \\
\text { measures (but still remain em- } \\
\text { ployed) }\end{array}$ & 74 & $15.4 \%$ \\
\hline $\begin{array}{l}\text { No longer have a job due to } \\
\text { COVID-19 measures }\end{array}$ & 12 & $2.5 \%$ \\
\hline $\begin{array}{l}\text { Had not worked even before the } \\
\text { COVID-19 pandemic }\end{array}$ & 51 & $10.6 \%$ \\
\hline $\begin{array}{l}\text { Experiencing symptoms of } \\
\text { COVID-19 infection }\end{array}$ & - & - \\
\hline Yes & 16 & $3.3 \%$ \\
\hline Unsure & 66 & $13.7 \%$ \\
\hline No & 400 & $83.0 \%$ \\
\hline $\begin{array}{l}\text { Hours per day browsing } \\
\text { COVID-19 information online } \\
\text { in the past two weeks } \\
(\text { Mean } \pm \text { SD) }\end{array}$ & $1.37 \pm 1.33$ & - \\
\hline \multicolumn{3}{|l|}{ Depression level } \\
\hline Minimal & 143 & $29.7 \%$ \\
\hline Mild & 83 & $17.2 \%$ \\
\hline Moderate & 146 & $30.3 \%$ \\
\hline Severe & 110 & $22.8 \%$ \\
\hline \multicolumn{3}{|l|}{ Anxiety level } \\
\hline Minimal & 156 & $32.8 \%$ \\
\hline Mild & 149 & $31.3 \%$ \\
\hline Moderate & 89 & $18.7 \%$ \\
\hline Severe & 82 & $17.2 \%$ \\
\hline
\end{tabular}

Table 2 shows the univariate analysis of the screened variables. The Mann-Whitney test, One-way Anova test and Kruskal-Wallis test are used when independent variables 
are binary (gender and chronic health issue), continuous (age, number of children under the age of 18, exercise and hours per day browsing COVID-19 related information online) and categorical (education, employment status and experiencing symptoms of COVID-19 infection) respectively. Gender $(\mathrm{p}=0.001)$, age $(\mathrm{p}<0.001)$, education level $(\mathrm{p}=0.001)$, occupation $(\mathrm{p}=0.003)$, number of children $(\mathrm{p}=0.019)$, exercise $(\mathrm{p}<0.001)$, experiencing symptoms of COVID-19 infection $(p<0.001)$ and hours per day browsing COVID-19 information online $(p=0.009)$ have significant effects on depression.

For anxiety, gender $(\mathrm{p}=0.001)$, age $(\mathrm{p}<0.001)$, education level $(\mathrm{p}=0.001)$, employment status $(p=0.006)$, exercise $(p<0.001)$, experiencing symptoms of COVID-19 infection $(p<0.001)$ and hours per day browsing COVID-19 information online $(p<0.001)$ are also significant. Contrarily, number of children and having chronic disease are non-significant $(p>0.05)$. Considering the number of children is known from previous studies [41-43] to have a significant impact on adults' mental health, we keep the number of children under the age of 18 in the ordinal regression model.

Table 2. Univariate analysis of depression and anxiety.

\begin{tabular}{|c|c|c|c|c|}
\hline \multirow[t]{2}{*}{ Variables } & \multicolumn{2}{|c|}{ Depression } & \multicolumn{2}{|c|}{ Anxiety } \\
\hline & Statistics & $\mathrm{p}$ & Statistics & $\mathrm{p}$ \\
\hline Gender & 3.439 a & 0.001 & $3.253^{\mathrm{a}}$ & 0.001 \\
\hline Age & $2.313 \mathrm{~b}$ & 0.000 & $2.292 \mathrm{~b}$ & 0.000 \\
\hline Education & $14.065^{\mathrm{c}}$ & 0.001 & $15.142^{c}$ & 0.001 \\
\hline Employment status & $11.792^{\mathrm{c}}$ & 0.003 & $10.175^{c}$ & 0.006 \\
\hline Number of children under the age of 18 & $3.329 \mathrm{~b}$ & 0.019 & $2.249^{b}$ & 0.082 \\
\hline Chronic health issue & $-0.678^{a}$ & 0.498 & $-1.056^{a}$ & 0.291 \\
\hline Exercise hours per day & $3.742 \mathrm{~b}$ & 0.000 & $4.172 \mathrm{~b}$ & 0.000 \\
\hline Experiencing symptoms of COVID-19 infection & $15.693^{c}$ & 0.000 & $15.800^{c}$ & 0.000 \\
\hline $\begin{array}{c}\text { Hours per day browsing COVID-19 information } \\
\text { online }\end{array}$ & $2.578^{b}$ & 0.009 & $3.618^{b}$ & 0.000 \\
\hline
\end{tabular}

a Mann-Whitney test (when independent variable is binary); b One-way Anova test (when independent variable is continuous);. c Kruskal-Wallis test (when independent variable is polytomous)

In an ordinal multi-class logistic regression model, the results of a parallel line test $(\chi 2=28.835, p=0.150>0.05)$ showed the regression equations were parallel to each other and could be analyzed by an ordinal logistic model. The model fit was good with statistical significance $(p<0.001)$. Similarly, the parallel line test results $(\chi 2=21.764, p=0.474)$ and the degree of model fit $(p<0.001)$ with anxiety as the independent variable were good. The results of the ordinal multi-class logistic regression are in Table 3. 
Table 3. Results of ordinal multi-class logistic regression

\begin{tabular}{|c|c|c|c|c|c|c|c|c|}
\hline \multirow[t]{2}{*}{ Factors } & \multicolumn{4}{|c|}{ Depression } & \multicolumn{4}{|c|}{ Anxiety } \\
\hline & OR & OR $(95 \% \mathrm{CI})$ & SE & $\mathrm{p}$ & OR & OR $(95 \%$ CI $)$ & SE & $\mathrm{p}$ \\
\hline \multicolumn{9}{|l|}{ Gender } \\
\hline Male & 0.596 & $(0.425,0.837)$ & 0.173 & 0.003 & 0.605 & $(0.430,0.852)$ & 0.175 & 0.004 \\
\hline Female (reference group) & - & - & - & - & - & - & - & - \\
\hline Age & 0.952 & $(0.937,0.967)$ & 0.008 & 0.000 & 0.954 & $(0.939,0.969)$ & 0008 & 0.000 \\
\hline \multicolumn{9}{|l|}{ Education } \\
\hline Middle school & 2.000 & $(0.305,13.131)$ & 0.960 & 0.470 & 6.342 & $(0.951,42.306)$ & 0.968 & 0.056 \\
\hline High school & 1.077 & $(0.664,1.745)$ & 0.246 & 0.765 & 1.302 & $(0.804,2.110)$ & 0.246 & 0.283 \\
\hline $\begin{array}{l}\text { College/university degree or } \\
\text { higher (reference group) }\end{array}$ & - & - & - & - & - & - & - & - \\
\hline \multicolumn{9}{|l|}{ Occupation } \\
\hline Self-employed & 0.799 & $(0.508,1.259)$ & 0.232 & 0.334 & 0.615 & $(0.388,0.976)$ & 0.276 & 0.039 \\
\hline $\begin{array}{l}\text { Unemployed status (student, } \\
\text { unemployed and retired) }\end{array}$ & 0.845 & $(0.539,1.326)$ & 0.230 & 0.465 & 0.564 & $(0.357,0.890)$ & 0.233 & 0.014 \\
\hline Employee (reference group) & - & - & - & - & - & - & - & - \\
\hline $\begin{array}{c}\text { Number of children under the } \\
\text { age of } 18\end{array}$ & 0.729 & $(0.580,0.916)$ & 0.117 & 0.007 & 0.785 & $(0.624,0.988)$ & 0.117 & 0.039 \\
\hline Exercise (hours) & 0.859 & $(0.764,0.966)$ & 0.060 & 0.011 & 0.909 & $(0.809,1.022)$ & 0.060 & 0.110 \\
\hline \multicolumn{9}{|l|}{$\begin{array}{l}\text { Experiencing symptoms of } \\
\text { COVID-19 infection }\end{array}$} \\
\hline Yes & 2.326 & $(0.918,5.896)$ & 0.475 & 0.075 & 1.721 & $(0.684,4.329)$ & 0.471 & 0.248 \\
\hline Unsure & 2.160 & $(1.300,3.590)$ & 0.260 & 0.003 & 2.036 & $(1.236,3.354)$ & 0.255 & 0.005 \\
\hline No (reference group) & - & - & - & - & - & - & - & - \\
\hline $\begin{array}{l}\text { Hours per day browsing } \\
\text { COVID-19 information online }\end{array}$ & 1.141 & $(1.005,1.296)$ & 0.065 & 0.041 & 1.165 & $(1.026,1.322)$ & 0.065 & 0.018 \\
\hline
\end{tabular}


Table 3 reveals that males had a lower likelihood of depression during the epidemic $(\mathrm{OR}=0.596,95 \% \mathrm{CI}=.425-.837)$ than females did. Adults' age $(\mathrm{OR}=0.952,95 \% \mathrm{CI}=.937$ $-.967)$, number of children $(\mathrm{OR}=0.729,95 \% \mathrm{CI}=.580-.916)$ and daily exercise time (OR $=0.859,95 \% \mathrm{CI}=.764-.966)$ negatively predicted depression, and adults who were unsure whether they had experienced symptoms of COVID-19 infection were more likely to experience depression $(\mathrm{OR}=2.160,95 \% \mathrm{CI}=1.300-3.590)$. Hours per day browsing COVID-19 information online predicted depression positively (OR $=1.141,95 \% \mathrm{CI}=1.005$ $-1.296)$.

Similarly, males were less likely to experience anxiety than females were (OR $=0.619$, $95 \% \mathrm{CI}=.438-.876)$. Age $(\mathrm{OR}=0.954,95 \% \mathrm{CI}=.939-.969)$ and the number of children $(\mathrm{OR}=0.785,95 \% \mathrm{CI}=.624-.988)$ negatively predicted anxiety. Additionally, people who were unsure whether they had COVID-19 infection ( $\mathrm{OR}=2.036,95 \% \mathrm{CI}=1.236-3.354)$ and who spent more time browsing COVID-19 information online $(\mathrm{OR}=1.165,95 \% \mathrm{CI}=$ 1.026 - 1.322) were more likely to have anxiety symptoms. Other variables in the model, such as education, had no significant predictive effect on either depression or anxiety.

\section{Discussion}

The COVID-19 pandemic has had a massive impact on people's lives, especially in Brazil due to the limited health system capacity to deal with the COVID-19 crisis [44]. Nonetheless, to date, few studies have examined the mental health conditions of adults in Brazil, which leads the world in daily COVID-19 cases and death in 2020. In our study, close to half of the adults were unable to work in their normal workplaces. The results of our survey of adults in Brazil reveal the prevalence of depressive symptoms was $70.3 \%$, and the incidence of severe depressive symptoms was $22.8 \%$; the incidence rates of anxiety symptoms and severe anxiety symptoms were $67.2 \%$ and $17.2 \%$ respectively. Several recent studies before COVID-19 reported the incidence of anxiety in Brazilians was $18.0 \%$ in year 2018 [45] and the average incidence of depression in Brazilians was $4.1 \%$ in year 2013 [46], which were much lower than our results which are the prevalence rates after the initial COVID-19 outbreak. Given Brazil is the largest country in South America, to better benchmark and interpret our findings, we list the major mental health studies in Latin America during the COVID-19 pandemic to date to provide more comprehensive evidence on the mental burden among Brazilian adults (see Table 4). The table reveals the prevalence rates in our study in Brazil are higher than many studies in other South American countries such as $47.0 \%$ prevalence of depressive symptoms and $54.9 \%$ of anxiety symptoms in Argentina [47], 19.2\% prevalence of psychological distress in Chile [48], 34.9\% prevalence of depressive symptoms [49], and $21.7 \%$ of severe anxiety symptoms and $26.1 \%$ of severe mental distress in Peru [2]. 
Table 4. Prevalence rates of mental issues during the COVID-19 pandemic in South America.

\begin{tabular}{|c|c|c|c|c|c|}
\hline Study & Duration & Country & Sample & Instruments and cut-off point & Mental health indicators \\
\hline $\begin{array}{l}\text { Torrente et } \\
\text { al. (2020) } \\
\quad[47]\end{array}$ & $\begin{array}{l}\text { March } 24 \\
\text { to March } \\
27,2020\end{array}$ & $\begin{array}{l}\text { Argen- } \\
\text { tina }\end{array}$ & $\begin{array}{c}\text { Adults } \\
(\mathrm{N}=10,053)\end{array}$ & $\begin{array}{c}\text { PHQ-9 } \\
(6,9 \text {, and } 15 \text { as the cut-off points }) \\
\text { GAD-7 } \\
(5,10 \text {, and } 15 \text { as the cut-off points })\end{array}$ & $\begin{array}{c}\text { 47.1\% prevalence of anxiety symptoms } \\
\text { (18.5\% mild, } 18.1 \% \text { moderate and } 10.5 \% \\
\text { severe symptoms) } \\
\mathbf{5 4 . 9 \%} \text { prevalence of depressive symp- } \\
\text { toms (31.6\% mild, } 13.6 \% \text { moderate and } \\
\quad 9.6 \% \text { severe symptoms) }\end{array}$ \\
\hline $\begin{array}{l}\text { Duarte \& } \\
\text { Jimé- } \\
\text { nez-Molina } \\
(2020)[48] \\
\end{array}$ & $\begin{array}{l}\text { Between } \\
\text { May and } \\
\text { June } 2020\end{array}$ & Chile & $\begin{array}{c}\text { Adults } \\
(\mathrm{N}=1078)\end{array}$ & $\begin{array}{c}\text { PHQ-4 } \\
\text { (6 as the cut-off point of preva- } \\
\text { lence) }\end{array}$ & $\begin{array}{l}19.2 \% \text { prevalence of psychological dis- } \\
\text { tress }\end{array}$ \\
\hline
\end{tabular}

\begin{tabular}{|c|c|c|c|}
\hline $\begin{array}{c}\text { Herrera et } \\
\text { al. (2020) } \\
{[50]}\end{array}$ & $\begin{array}{l}\text { Between } \\
\text { June and } \\
\text { September } \\
2020\end{array}$ & Chile & $\begin{array}{l}\text { Older adults } \\
\qquad(\mathrm{N}=720)\end{array}$ \\
\hline $\begin{array}{l}\text { Paz et al. } \\
\text { (2020) [51] }\end{array}$ & $\begin{array}{c}\text { March } 22 \\
\text { to April 18, } \\
2020\end{array}$ & Ecuador & $\begin{array}{c}\text { Confirmed or } \\
\text { suspected } \\
\text { COVID-19 patien } \\
(\mathrm{N}=759)\end{array}$ \\
\hline $\begin{array}{l}\text { Chen et al. } \\
\text { (2020) [52] }\end{array}$ & $\begin{array}{c}\text { April } 10 \text { to } \\
\text { May 2, } \\
2020\end{array}$ & Ecuador & $\begin{array}{c}\text { Healthcare work } \\
\text { ers }(\mathrm{N}=252)\end{array}$ \\
\hline $\begin{array}{c}\text { Romero } \\
\text { Parra (2020) } \\
{[53]}\end{array}$ & $\begin{array}{l}\text { Do not } \\
\text { report }\end{array}$ & $\begin{array}{l}\text { Peru, } \\
\text { Vene- } \\
\text { zuela }\end{array}$ & $\begin{array}{c}\text { University } \\
\text { students } \\
(\mathrm{N}=600)\end{array}$ \\
\hline
\end{tabular}

PHQ-9

$(6,9$, and 15 as the cut-off points) $\quad \mathbf{3 0 . 1 8} \%$ prevalence of depressive sympGeriatric Anxiety Inventory - Short Form (GAISF) (3 as the cut-off point of prevalence)

$$
\text { PHQ-9 }
$$

$(6,9$, and 15 as the cut-off points)

GAD-7

$(5,10$, and 15 as the cut-off points)

$\mathbf{4 2 . 8 5} \%$ prevalence of anxiety symptoms toms $\mathbf{2 0 . 3} \%$ prevalence of depressive symptoms

$\mathbf{2 2 . 5} \%$ prevalence of anxiety symptoms

GAD-7
$(5,10$, and 15 as the cut-off points) K-6 $(5,13$ as the cut-off points)

$\mathbf{3 2 . 5 \%}$ prevalence of distress disorder

$\mathbf{2 8 . 2} \%$ prevalence of anxiety symptoms Beck Depression Inventory (BDI-2) $\quad \mathbf{3 4 . 7} \%$ prevalence of depressive symp$(14,20$, and 29 as the cut-off points) toms of university students in Peru (18.4\% mild, $11.2 \%$ moderate, $5.1 \%$ severe symptoms)

$\mathbf{1 1 . 4} \%$ prevalence of depressive symptoms of university students in Venezuela (6.4\% mild, 5.0\% moderate symptoms)

\begin{tabular}{cccc}
\hline $\begin{array}{c}\text { Antiporta et } \\
\text { al. (2021) }\end{array}$ & $\begin{array}{c}\text { May } 4 \text { to } \\
\text { May 16, }\end{array}$ & Peru & $\begin{array}{c}\text { Adult Peruvian } \\
\text { residents } \\
(49]\end{array}$ \\
2020 & & $(\mathrm{~N}=57,446)$ & PHQ-9 \\
\hline
\end{tabular}

\section{GAD-7}

\begin{tabular}{|c|c|c|c|c|}
\hline Yañez et al. & $\begin{array}{l}\text { April } 10 \text { to } \\
\text { May 2, }\end{array}$ & Peru & $\begin{array}{l}\text { Healthcare work- } \\
\text { ers }\end{array}$ & $\begin{array}{l}(5,10 \text {, and } 15 \text { as the cut-off points) } \\
\text { K-6 }(5,13 \text { as the cut-off points) }\end{array}$ \\
\hline & 2020 & & $(\mathrm{~N}=303)$ & \\
\hline
\end{tabular}

\begin{tabular}{lcc}
\hline $\begin{array}{l}\text { Martínez et } \\
\text { al. (2020) } \\
{[54]}\end{array}$ & April $2020 \begin{array}{c}\text { Adults, college } \\
\text { Colom- } \\
\text { bia }\end{array}$ & $\begin{array}{c}\text { students, and in- } \\
\text { formal workers } \\
(\mathrm{N}=984)\end{array}$ \\
\hline
\end{tabular}

Zhang et al. March 25 (2021) [21] to March 28, 2020
Not reported

$(\mathrm{N}=984)$ Index (CPDI) $\mathbf{3 4 . 9} \%$ prevalence of depressive symptoms

Mean of GAD-7 anxiety scale is 15.4

Mean of K6 distress scale is 19.2

$\mathbf{2 1 . 7} \%$ prevalence of severe anxiety symptoms

$\mathbf{2 2 . 5 \%}$ prevalence of severe mental distress

Mean of anxiety and stress score is 6.5 (scale 0-10)

Mean of depressed score is 3.8 (scale 0-10)

COVID-19 Peritraumatic Distress Mean score of COVID-19 Peritraumatic

Distress Index (CPDI) was 37.64 (score 0-100)

$\mathbf{7 1 . 8} \%$ prevalence of peritraumatic distress $(52.0 \%$ mild or moderate, $18.8 \%$ severe distress)

Our regression analysis reveals that females had higher likelihood of depression and anxiety symptoms, a finding that is in line with the previous research on gender and mental health [55]. Older adults and those with more children were less likely to experience anxiety and depression symptoms [56]. Adults who exercised more per day dur- 
ing the pandemic had a lower likelihood of depression symptoms, supporting the view that exercise might help relieve the buildup of depressive symptoms [57]. Employees, compared with the unemployed or self-employed, were more likely to have anxiety but not depressive symptoms. Such a finding differs from the literature that suggests occupational stressors may cause both depression and anxiety in existing studies [58]. Our findings on the higher anxiety symptoms of employees suggest COVID-19 may present some unique challenges on anxiety across employment status groups. The higher anxiety symptoms experienced by employees might be related to the drastic changes in the work environment during COVID-19, while self-employed individuals and non-working groups do not have such trouble. In addition, a potential reason why our study did not find an association between occupation and anxiety is that not all kinds and levels of occupational stress might carry a significant relationship with depressive symptoms [59].

Individuals' hours per day browsing COVID-19 information online positively predicted depression and anxiety, suggesting online information on crises might exacerbate mental disorders [60-61]. Altogether, our findings identified several predictors which enable psychiatrists and healthcare organizations to better identify and focus on the more vulnerable sub-populations. Furthermore, our results may enable psychiatry practitioners to identify potential patients with depressive and anxiety symptoms during the COVID-19 pandemic.

\section{Limitation and future research}

The study has certain limitations. Firstly, we designed a cross-sectional study, which yields a snapshot rather than a dynamic picture, and we suggest longitudinal designs in future research. Another potential limitation regarding our sampling procedures is that although the sample covered much of Brazil geographically, it was not entirely representative of the population due to our online survey, because only $71 \%$ of the population has access to the Internet in Brazil. Our small sample size may raise concerns about generalizability. In future research it would be especially interesting to investigate populations that do not have internet access. Although it was proposed that web surveys had an 11 percentage points lower response rate than other survey modes [62], we still cannot ignore the non-response bias problem that may be caused by low response rates in this study (56.2\%). Future research can focus on increasing the response rate and sample size to extend our findings. Brazil is a very large country, and research on mental health during COVID-19 in Latin America remains underdeveloped, calling for more research to generate evidence to better cope with the ongoing pandemic [63]. We hope our results help to gather data for evidence-based decisions on mental health for Brazil, one of the largest and worst-affected countries in the COVID-19 crisis. 


\section{Conclusions}

This study reported $70.3 \%$ prevalence of depressive symptoms (17.2\% mild, $30.3 \%$ moderate and $22.8 \%$ severe symptoms) and $67.2 \%$ prevalence of anxiety symptoms $(31.3 \%$ mild, $18.7 \%$ moderate and $17.2 \%$ severe symptoms) among Brazilian adults ( $\mathrm{N}=482)$ during the COVID-19 pandemic. Gender, age, number of children, being employed and time browsing COVID-19 information online are potential predictors of experiencing depressive and anxiety symptoms. The incidence of anxiety and depressive symptoms in the Brazilian adult population was much higher after the initial outbreak than the pre-pandemic rates, indicating Brazilians' mental health has suffered during the COVID-19 pandemic. Healthcare organizations can use our findings to identify groups mentally vulnerable to COVID-19 in Brazil. Better identification of the mentally vulnerable population can enable more targeted effort to reduce the high prevalence of mental health symptoms in Brazil. Beside psychiatric identification and resource prioritization, policy-makers can direct and promote more reliable information on the pandemic online, which has been a source of mental health issues in the pandemic. The findings of this study quantify the prevalence rates of depression and anxiety symptoms in Brazil and identify several predictors, which can enable psychiatrists and healthcare organizations to better identify the more vulnerable sub-populations and provide evidence to deploy resources as well as create opportunities for timely pre-emption and prevention.

Author Contributions: Conceptualization, S.X.Z. and H.H.; methodology, S.X.Z. and H.H.; software, S.X.Z. and H.H.; validation, S.X.Z. and H.H.; formal analysis, S.X.Z. and H.H.; investigation, S.X.Z., H.H. and J.L.; resources, S.X.Z., H.H. and J.L.; writing-original draft preparation, S.X.Z. and H.H.; writing-review and editing, S.X.Z. and H.H.; supervision, S.X.Z.; visualization, H.H.; data curation, M.A., S.F.P. and J.A.S.; project administration, S.X.Z. and J.A.S. All authors have read and agreed to the published version of the manuscript. Authorship must be limited to those who have contributed substantially to the work reported.

Funding: We acknowledge the support from National Natural Science Foundation of China [grant number 71772103].

Informed Consent Statement: Informed consent was obtained from all subjects involved in the study.

Data Availability Statement: Data are available upon request.

Conflicts of Interest: The authors declare no conflict of interest.

\section{References}

1. Kawohl, W.; Nordt, C. COVID-19, unemployment, and suicide[J]. Lancet Psychiatry. 2020, 7(5):389-390.

2. Yáez, J.A.; Jahanshahi, A.A.; Alvarez-Risco, A.; et al. Anxiety, distress, and turnover intention of healthcare workers in Peru by their distance to the epicenter during the COVID-19 crisis[J]. Am. J. Trop. Med. Hyg. 2020, 103(4):1614-1620. DOI: 10.4269/ajtmh.20-0800

3. Zhang, S.X.; Sun, S.; Jahanshahi. A.A.; et al. Developing and testing a measure of COVID-19 organizational support of healthcare workers - Results from Peru, Ecuador, and Bolivia[J]. Psychiatry Res. 2020, 291:113174. DOI : 10.1016/j.psychres.2020.113174

4. Zhang, S.X.; Chen J.; Jahanshahi, A.A. , et al. Succumbing to the COVID-19 pandemic-healthcare workers not satisfied and intend to leave their jobs[J]. Int. J. Mental Health Addict. 2021. DOI: 10.1007/s11469-021-00502-5

5. Marinho, P.R.D; Cordeiro, G.M.; Coelho, H.F.C. COVID-19 in Brazil: A sad scenario[J]. Cytokine Growth Factor Rev. 2020, In Press. DOI: 10.1016/j.cytogfr.2020.10.010 
6. Lobo, A.D.P.; Cardoso-dos-Santos, A.C.; Rocha, M.S.; et al. COVID-19 epidemic in Brazil: where are we at?[J]. Cytokine Growth Factor Rev. 2020,97:382-385. DOI: 10.1016/j.ijid.2020.06.044

7. Sun, S.; Zhang, S.X.; Jahanshahi, A.A.; et al. Drilling under the COVID - 19 pandemic: A diary study of professional football players' mental health and workout perforance[J]. Stress Health. 2021. DOI: 10.1002/smi.3059

8. Lateef, T.; Chen, J.; Tahir, M.; et al. Typhoon eye effect versus ripple effect: the role of family size on mental health during the COVID-19 pandemic in Pakistan[J]. Global. Health. 2021, 17(1):32. DOI: 10.1186/s12992-021-00685-5

9. Gong, H.T.; Zhang, S.X.; Nawaser, K.; et al. The mental health of healthcare staff working during the COVID-19 crisis: their working hours as a boundary condition[J]. J. Multidiscip. Healthc. 2021, 14:1073-1081. DOI: 10.2147/JMDH.S297503

10. Zhang, S.X.; Wang, Y.; Rauch, A.; Wei, F. Unprecedented disruptions of lives and work: Health, distress and life satisfaction of working adults in China one month into the COVID-19 outbreak[J]. Psychiatry Res. 2020, 288, 112958. DOI: 10.1016/j.psychres.2020.112958

11. da Silva, A.G.; Miranda, D.M.; Diaz, A.P.; Telles, A.L.S.; Malloy-Diniz, L.F.; Palha, A.P. Mental health: why it still matters in the midst of a pandemic. Braz J Psychiatry. 2020, 42:229-231. http:// dx.doi.org/10.1590/1516-4446-2020-0009

12. Xiang, Y.T.; Yang, Y.; Li, W.; et al. Timely mental health care for the 2019 novel coronavirus outbreak is urgently needed[J]. Lancet Psychiatry. 2020, 7(3):228-229. DOI:10.1016/S2215-0366(20)30046-8

13. Pierce, M.; Hope, H.; Ford, T.; et al. Mental health before and during the COVID-19 pandemic: A longitudinal probability sample survey of the UK population[J]. Lancet Psychiatry.2020,7(10):883-892.DOI: 10.1016/ S2215-0366(20)30308-4.

14. Unützer, J.; Kimmel, R.J.; Snowden, M. Psychiatry in the age of COVID-19[J]. World Psychiatry, 2020, 19(2):130-131. DOI: 10.1002/wps.20766

15. Amsalem, D.; Dixon, L.B.; Neria, Y. The coronavirus disease 2019 (COVID-19) outbreak and mental health: current risks and recommended actions[J]. JAMA Psychiatry. 2020, 78(1):e1-e2. DOI: 10.1001/jamapsychiatry.2020.1730

16. Peng, M.; Wang, L.; Xue, Q.; et al. Post-COVID-19 epidemic: allostatic load among medical and nonmedical workers in China[J]. Psychother. Psychosom. 2020, 1-10. DOI:10.1159/000511823

17. Dai, H.; Zhang, S.X.; Looi, K.H.; et al. Perception of health conditions and test availability as predictors of adults' mental health during the COVID-19 pandemic: A survey study of adults in Malaysia[J]. Int. J. Environ. Res. Public Health. 2020, 17(15). DOI: $10.3390 /$ ijerph17155498

18. Schfer, S.; Sopp, M.R.; Schanz, C.; et al. Impact of COVID-19 on public mental health and the buffering effect of a sense of coherence[J]. Psychother. Psychosom. 2020, 89(6):1-7. DOI:10.1159/000510752

19. Wang, C.; Pan, R.; Wan, X.; et al. Immediate psychological responses and associated factors during the initial stage of the 2019 coronavirus disease (COVID-19) epidemic among the general population in China[J]. Int. J. Environ. Res. Public Health. 2020, 17(5):1729. DOI: 10.3390/ijerph17051729

20. Rajkumar, R.P. COVID-19 and mental health: A review of the existing literature[J]. Asian J. Psychiatr. 2020, 52:102066. DOI: 10.1016/j.ajp.2020.102066

21. Zhang, S.X.; Wang, Y.; Jahanshahi, A.A.; et al. Early evidence and predictors of mental distress of adults one month in the COVID-19 epidemic in Brazil[J]. J. Psychosomat. Res. 2021, 142:110366. DOI: 10.1016/j.jpsychores.2021.110366

22. McElroy, E.; Patalay, P.; Moltrecht, B.; et al. Demographic and health factors associated with pandemic anxiety in the context of COVID-19[J]. Br. J. Health Psychol., 2020, 25:934 - 944. DOI:10.1111/bjhp.12470

23. Kabasakal, E.; Zpulat, F.; Ayegül, A.; et al. Mental health status of health sector and community services employees during the COVID-19 pandemic[J]. Int. Arch. Occup. Environ. Health, 2021:1-14. DOI: 10.1007/s00420-021-01678-y

24. Dong, H.; Hu, R.; Lu, C.; et al. Investigation on the mental health status of pregnant women in China during the pandemic of COVID-19[J]. Arch. Gynecol. Obstet., 2020, 303(2):463-469. DOI: 10.1007/s00404-020-05805-x

25. Broche-Pérez, Y.; Fernández-Fleites, Z.; Jiménez-Puig, E.; et al. Gender and fear of COVID-19 in a Cuban population sample[J]. Int. J. Mental Health Addict., 2020(1). DOI: 10.1007/s11469-020-00343-8 
26. Simha, A.; Prasad, R.; Ahmed, S.; et al. Effect of gender and clinical-financial vulnerability on mental distress due to COVID-19[J]. Arch. Womens Ment. Health, 2021, 23(1). DOI: 10.1007/s00737-020-01097-x

27. Ausin, B.; González-Sanguino, C.; Castellanos, M.N.; et al. Gender-related differences in the psychological impact of confinement as a consequence of COVID-19 in Spain[J]. J. Gend. Stud. 2020(9):1-10. DOI: 10.1080/09589236.2020.1799768

28. Schweda, A.; Weismüller, B.; Buerle, A.; et al. Phenotyping mental health: Age, community size, and depression differently modulate COVID-19-related fear and generalized anxiety[J]. Compr. Psychiat. 2021, 104(152218). DOI : 10.1016/j.comppsych.2020.152218

29. Malkawi, S.H.; Almhdawi, K.; Jaber, A.F.; et al. COVID-19 quarantine-related mental health symptoms and their correlates among mothers: A cross sectional study[J]. Matern. Child Health J. 2021, 25(5): 695-705. DOI: 10.1007/s10995-020-03034-x

30. Zhang, C.Q.; Zhang, R.; Lu, Y.; et al. Occupational stressors, mental health, and sleep difficulty among nurses during the COVID-19 pandemic: The mediating roles of cognitive fusion and cognitive reappraisal[J]. J. Contextual Behav. Sci. 2021, 19(7):64-71. DOI:10.1016/j.jcbs.2020.12.004

31. Fitzpatrick, O.; Carson, A.; Weisz, J.R. Using mixed methods to identify the primary mental health problems and needs of children, adolescents, and their caregivers during the Coronavirus (COVID-19)[J]. Child Psychiat. Hum. Dev. 2020:1-12. DOI: 10.1007/s10578-020-01089-z

32. Delamater, A.M.; Guzman, A.; Aparicio, K.; et al. Mental health issues in children and adolescents with chronic illness[J]. International Journal of Human Rights in Healthcare, 2017. DOI: 10.1108/IJHRH-05-2017-0020

33. Jahanshahi, A.A.; Dinani, M.M.; Madavani, A.N.; et al. The distress of Iranian adults during the COVID-19 pandemic - More distressed than the Chinese and with different predictors[J]. Brain Behav. Immun. 2020, 87:124-125. DOI:10.1016/j.bbi.2020.04.081

34. Yang, K.M.; Banamah, A. Quota Sampling as an alternative to probability sampling? An experimental study[J]. Sociol. Res. Online. 2014, 19(1):29. DOI: 10.5153/sro.3199

35. Kroenke, K.; Spitzer, R.L.; Williams, J.B.W. The PHQ-9: validity of a brief depression severity measure[J]. J. Gen. Intern. Med. 2001,16:606-613. DOI:10.1046/j.1525-1497.2001.016009606.x

36. Spitzer, R.L.; Kroenke, K.; Williams, J.B.; et al. A brief measure for assessing generalized anxiety disorder: the GAD-7[J]. Arch. Intern. Med. 2006, 166(10):1092-1097. DOI: 10.1001/archinte.166.10.1092

37. Kroenke, K. PHQ-9: global uptake of a depression scale[J]. World Psychiatry: official journal of the World Psychiatric Association (WPA). 2021,20(1):135-136. DOI: 10.1002/wps.20821

38. Urtasun, M.; Daray, F.M.; Teti, G.L.; et al. Validation and calibration of the patient health questionnaire (PHQ-9) in Argentina[J]. BMC Psychiatry. 2019, 19(1):291.DOI:10.1186/s12888-019-2262-9

39. Cao, W.; Fang, Z.; Hou, G.; et al. The psychological impact of the COVID-19 epidemic on college students in China[J]. Psychiatry Res. 2020, 287:112934. DOI: 10.1016/j.psychres.2020.112934

40. Abdellatif, W.; Ding, J.; Jalal, S.; et al. Lack of gender disparity among administrative leaders of Canadian health authorities[J]. J. Womens Health. 2020, 29(11). DOI: 10.1089/jwh.2019.7852

41. Ollivier, R.; Aston, M.; Price, S.; et al. Mental health \& parental concerns during COVID-19: The experiences of new mothers amidst social isolation[J]. Midwifery,2020, 94:102902. DOI:10.1016/j.midw.2020.102902

42. Almeida, M.; Shrestha, A.D.; Stojanac, D.; et al. The impact of the COVID-19 pandemic on women's mental health[J]. Arch. Womens Ment. Health. 2020,23:741-748. DOI:10.1007/s00737-020-01092-2

43. Agnafors, S.; Bladh, M.; Svedin, C.G.; Sydsj, G. Mental health in young mothers, single mothers and their children[J]. BMC Psychiatry.2019, 19(1): 1-7. DOI: 10.1186/s12888-019-2082-y

44. Abad, A.; Silva, J.; et al. Preparing for the COVID-19 mental health crisis in Latin America-Using early evidence from countries that experienced COVID-19 first[J]. Advances in Infectious Diseases. 2020, 10(3):40-44. DOI: 10.4236/aid.2020.103005 
45. Alonso, J.; Liu, Z.; Evans-Lacko, S.; et al. Treatment gap for anxiety disorders is global: Results of the World Mental Health Surveys in 21 countries[J]. Depress. Anxiety, 2018. 35(3): 195-208. doi:10.1002/da.22711.

46. Munhoz, T.N.; Nunes, B.P.; Wehrmeister, F.C.; et al. A nationwide population-based study of depression in Brazil[J]. J. Affect. Disord. 2016, 192:226-233.DOI:10.1016/j.jad.2015.12.038

47. Torrente, F.; Yoris, A.; Low, D.M.; et al. Sooner than you think: A very early affective reaction to the COVID-19 pandemic and quarantine in Argentina[J]. J. Affect. Disord. 2020, 282(2). DOI: 10.1016/j.jad.2020.12.124

48. Duarte, F.; Jiménez-Molina, A. Psychological distress during the COVID-19 epidemic in Chile: the role of economic uncertainty. Preprint, 2020. DOI: 10.1101/2020.09.27.20202648

49. Antiporta, D.A.; Cutipé Y.L.; Mendoza, M.; et al. Depressive symptoms among Peruvian adult residents amidst a National Lockdown during the COVID-19 pandemic[J]. BMC Psychiatry, 2021, 21(111). DOI: 10.1186/s12888-021-03107-3

50. Herrera, M.S.; Elgueta, R.; Fernández, M.B.; et al. A longitudinal study monitoring the quality of life in a national cohort of older adults in Chile before and during the COVID-19 outbreak[J]. BMC Geriatr. 2021, 21:143. DOI: 10.1186/s12877-021-02110-3

51. Paz, C.; Mascialino, G.; Adana-Díaz, L.; et al. Behavioral and sociodemographic predictors of anxiety and depression in patients under epidemiological surveillance for COVID-19 in Ecuador[J]. PLoS One, 2020, 15(9):e0240008. DOI : 10.1371/journal.pone.0240008

52. Chen, X.; Zhang, S.X.; Jahanshahi, A.A.; et al. Belief in conspiracy theory about COVID-19 predicts mental health and well-being: A study of healthcare staff in Ecuador (Preprint)[J]. JMIR Public Health and Surveillance. 2020, 6(3). DOI: $10.2196 / 20737$

53. Parra, M.R. Depression and the meaning of life in university students in times of pandemic[J]. International Journal of Educational Psychology. 2020, 9(3):223-242. DOI: 10.17583/ijep.2020.6784

54. Martínez, L.; Valencia, I.; Trofimoff, V. Subjective wellbeing and mental health during the COVID-19 pandemic: Data from three population groups in Colombia[J]. Data in Brief. 2020, 32(6):106287. DOI: 10.1016/j.dib.2020.106287

55. Zhang, S.X.; Liu, J; Jahanshahi, A.A.; et al. At the height of the storm: Healthcare staff's health conditions and job satisfaction and their associated predictors during the epidemic peak of COVID-19[J]. Brain Behav. Immun, 2020. DOI : 10.1016/j.bbi.2020.05.010

56. Roma, P.; Monaro, M.; Colasanti, M.; et al. A 2-month follow-up study of psychological distress among Italian people during the COVID-19 lockdown[J]. Int. J. Environ. Res. Public Health, 2020, 17(21). DOI: 10.3390/ijerph17218180

57. Razazian, N.; Yavari, Z.; Farnia, V.; et al. Exercising impacts on fatigue, depression, and paresthesia in female patients with multiple sclerosis[J]. Med. Sci. Sports Exerc. 2016, 48(5):796-803. DOI: 10.1249/mss.0000000000000834

58. Kim, H.R.; Sun, M.K.; Han, D.H.; et al. Protective and risk factors for depressive mood and anxiety against occupational stress: examining temperament character and coping strategy among civil servants[J]. Arch. Environ. Occup. Health, 2019(1):1-12. DOI: $10.1080 / 19338244.2019 .1666789$

59. Jung, J.; Jeong, I.; Lee, K.J.; et al. Effects of changes in occupational stress on the depressive symptoms of Korean workers in a large company: A longitudinal survey[J]. Annals of Occupational and Environmental Medicine, 2018, 30(1):39. DOI: 10.1186/s40557-018-0249-5

60. Nguyen, H.T.; Do, B.N.; Pham, K.M.; Kim, G.B.; Dam, H.T.B.; Nguyen, T.T.; et al. Fear of COVID-19 Scale-Associations of its scores with health literacy and health-related behaviors among medical students. Int J Environ Res Public Health. 2020, 17(11). DOI: $10.3390 /$ ijerph17114164

61. Carleton, R.N. Into the unknown: a review and synthesis of contemporary models involving uncertainty. J Anxiety Disord. 2016, 39:30-43. DOI: 10.1016/j.janxdis.2016.02.007

62. Daikeler, J.; Bonjak, M.; Manfreda, K.L. Web versus other survey modes: An updated and extended meta-analysis comparing response rates[J]. Journal of Survey Statistics and Methodology, 2020, 8(3):513-539. DOI: 10.1093/jssam/smz008 
415 63. Yan, J., Kim, S., Zhang, S. X., Foo, M. D., Alvarez-Risco, A., Del-Aguila-Arcentales, S., \& Yáñez, J. A. (2021). Hospitality workers' COVID-19 risk perception and depression: A contingent model based on transactional theory of stress model. International 417 Journal of Hospitality Management, 95, 102935. 